\title{
Clinicopathological differences between colonic and rectal carcinomas: are they based on the same mechanism of carcinogenesis?
}

\author{
K Konishi, T Fujii, N Boku, S Kato, I Koba, A Ohtsu, H Tajiri, A Ochiai, S Yoshida
}

\begin{abstract}
Background-There is a difference in the location of colorectal mucosal lesions and invasive cancers.

Aims-To ascertain whether the location of colorectal neoplasms reflects the carcinogenesis pathway.

Methods-The subject material consisted of 4147 neoplastic lesions that had been resected endoscopically or surgically from 5025 patients. Mucosal lesions and submucosal cancers were classified into depressed and non-depressed types endoscopically or histologically. The relations between macroscopic type, size, histology, and location were investigated. Results-(a) Non-depressed type. A total of 1774 of $3454(51 \%)$ mucosal lesions were located in the right colon, $1212(35 \%)$ in the left colon, and $468(14 \%)$ in the rectum. The incidence of mucosal lesions larger than $10 \mathrm{~mm}$ was $10 \%(185 / 1774)$ in the right colon, $21 \%(254 / 1212)$ in the left colon, and $27 \%(127 / 468)$ in the rectum. The incidence of mucosal lesions with villous components was $2 \%(32 / 1774)$ in the right colon, $5 \%(63 / 1212)$ in the left colon, and $13 \%(62 / 468)$ in the rectum. The ratio of submucosal cancers to mucosal lesions was significantly higher in the rectum $(0.064,30 / 469)$ than in the left $(0.034$, $43 / 1279)$ or right $(0.010,18 / 1857)$ colon. (b) Depressed type. The incidences of depressed type mucosal lesions and submucosal cancers were $5 \%(83 / 1857)$ and $17 \%$ $(3 / 18)$ in the right colon, $5 \%(67 / 1279)$ and $5 \%(2 / 43)$ in the left colon, and $0.2 \%(1 / 469)$ and $0 \%(0 / 30)$ in the rectum, respectively. Conclusion-There may be some mechanisms that promote the progression of mucosal lesions to invasive cancers in the left colon and rectum, whereas a de novo pathway from depressed type lesions may be implicated in some cancers of the right colon.

(Gut 1999;45:818-821)
\end{abstract}

Keywords: colorectal cancer; depressed cancer; carcinogenesis

The coexistence of adenomatous and cancerous components and sequential genetic alterations such as K-ras and p53 suggest that adenoma is a precursor of cancer. ${ }^{1-3}$ The adenoma-carcinoma sequence is generally accepted as a major pathway for the carcinogenesis of colorectal cancer. ${ }^{4-6}$ Morphologically these adenomas are protuberant lesions. However, many Japanese authors have reported flat or depressed type colorectal tumours, and state that these lesions are de novo carcinomas as they are not associated with adenomatous components, ${ }^{7-10}$ and that the incidence of K-ras mutation is low. ${ }^{11-14}$ Therefore flat or depressed type colorectal tumours may have a different pathway of carcinogenesis from the adenomacarcinoma sequence.

In the carcinogenesis of colorectal cancers, there may be a difference between the proximal colon and distal colon, as these two subsites originate embryologically from the midgut and hindgut. ${ }^{15}$ Bufill $^{16}$ and Delattre ${ }^{17}$ reported distinct genetic categories based on tumour location. It is not clear whether tumour location is related to the above carcinogenesis. In this study, we investigated the clinicopathological characteristics of colorectal tumours on the basis of their location.

\section{Methods}

SUBJECTS

A total of 5025 average risk patients underwent total colonoscopy using a videocolonoscope (CF200Z and CF200I; Olympus Optical Co., Tokyo, Japan) at the National Cancer Centre Hospital East from July 1992 to December 1997. Colonoscopy was repeated until all tumours, including diminutive $(\leqslant 5 \mathrm{~mm})$ polyps, had been resected endoscopically or surgically, and 4147 neoplastic lesions were used as the subject material in this study. The lesions of patients with familial adenomatous polyposis, hereditary non-polyposis colorectal cancer, and inflammatory bowel disease were excluded.

\section{LOCATION}

We categorised the location of the lesions into three groups according to the length of the colonoscope from the anus to the lesions: 0-15 cm, rectum; $16-40 \mathrm{~cm}$, left colon; $>41 \mathrm{~cm}$, right colon.

\section{MACROSCOPIC TYPE}

Macroscopically, mucosal lesions were classified into the depressed type and non-depressed type on the basis of the presence or absence of a depressed component determined endoscopically. Submucosal cancers were histologically classified as depressed or non-depressed according to the criteria of Kato et al. ${ }^{18}$ Briefly, lesions were defined as being of the depressed type when the edge of the lesion was depressed compared with the surrounding normal mu-
Accepted for publication 24 April 1999 

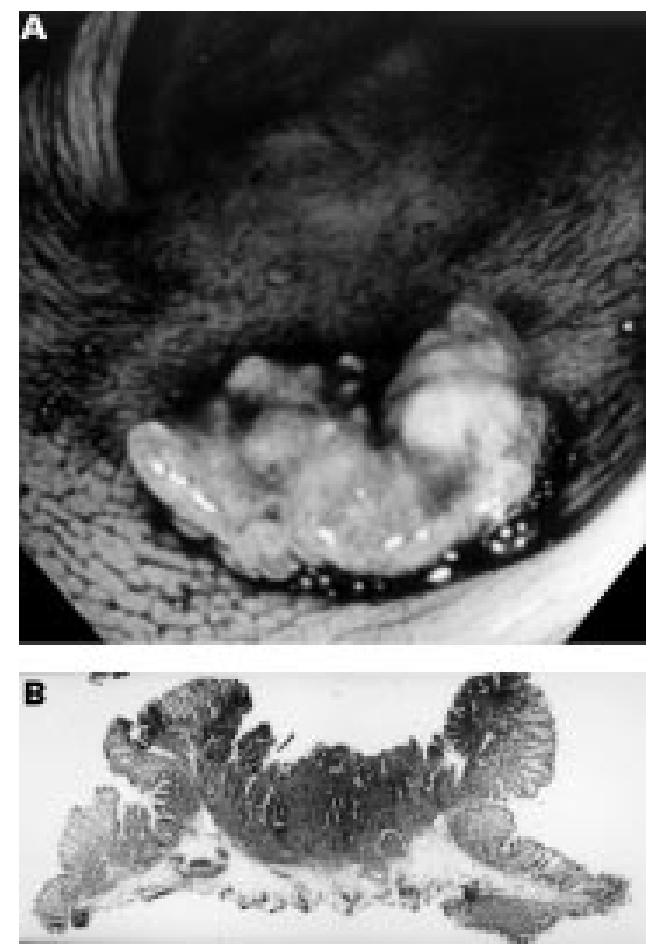

Figure 1 Morphological appearance of the depressed type of submucosal cancer. (A) Endoscopy shows a depressed cancer $11 \mathrm{~mm}$ diameter in size; (B) in the cross section of this lesion, the edge is depressed compared with the surrounding normal mucosa.

cosa, and were otherwise considered to be of the non-depressed type (fig 1). The macroscopic type of advanced cancer, which invaded beyond the submucosal layer, was not assessed.

ADENOMATOUS COMPONENT

In mucosal lesions, the presence or absence of a villous component was investigated histologically. In submucosal cancers, we investigated whether or not they were associated with an adenomatous component. Other clinicopathological features were determined according to the general rules of the Japanese Research Society for Cancer of the Colon and Rectum. ${ }^{19}$

STATISTICAL ANALYSIS

We compared the clinicopathological characteristics of lesions located in the rectum, left colon, and right colon using the $\chi^{2}$ test and Fisher's exact probability test. A value of $\mathrm{p}<0.05$ was considered significant.

\section{Results}

In total, 4147 neoplastic lesions were resected from 3087 patients. The average number of colonoscopic examinations was 1.85 (range $1-15)$, and the average number of lesions was 1.98 (range 1-14). In all, 684 lesions (16\%) were located in the rectum, $1493(36 \%)$ in the left colon, and 1970 (48\%) in the right colon. Macroscopically, 151 of 3605 mucosal lesions $(4 \%)$ and five of $91(5 \%)$ submucosal cancers were of the depressed type. Histologically, 3353 lesions (81\%) were adenomas, $252(6 \%)$ were intramucosal cancers, $91(2 \%)$ were submucosal cancers, and $451(11 \%)$ were advanced cancers.
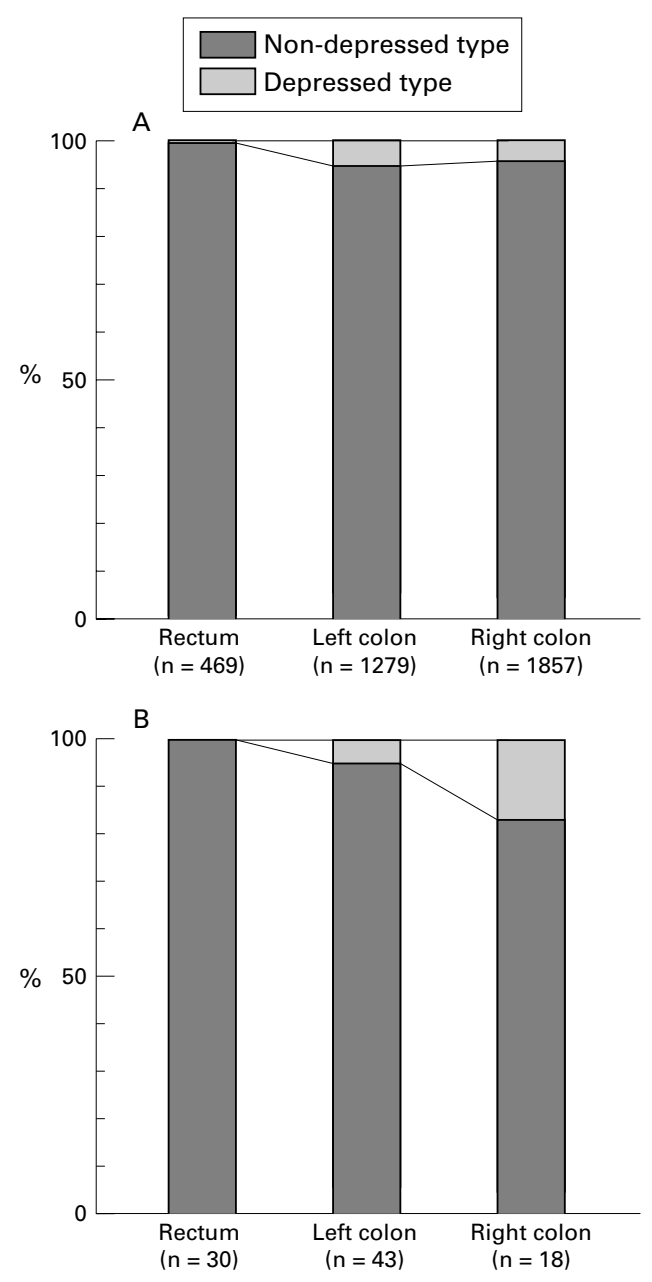

Figure 2 Comparison of the incidence of depressed and non-depressed types of neoplastic lesion in the rectum, left colon and right colon. (A) Mucosal lesions; (B) submucosal cancers. A significant difference in the macroscopic type was noted between the rectum and colon $(p<0.001)$. The incidence of depressed submucosal cancers in the right colon was significantly higher than that in the rectum $(p=0.0472)$.

LOCATION AND MACROSCOPIC TYPE OF MUCOSAL LESIONS AND SUBMUCOSAL CANCERS

Figure 2 shows the relation between the location and macroscopic type of mucosal lesions and submucosal cancers. Among the mucosal lesions, the incidence of the depressed type in the rectum $(0.2 \%, 1 / 469)$ was significantly lower than that in the left colon $(5.2 \%$, $67 / 1279)$ and the right colon $(4.5 \%, 83 / 1857)$ (rectum $v$ left colon, $\mathrm{p}<0.0001$; rectum $v$ right colon, $\mathrm{p}<0.0001$ ) (fig $2 \mathrm{~A}$ ). Among the submucosal cancers, the incidence of the depressed type in the rectum $(0 \%, 0 / 30)$ was lower than that in the left colon $(5 \%, 2 / 43)$ and the right colon $(17 \%, 3 / 18)$ (rectum $v$ right colon, $\mathrm{p}=$ 0.0472) (fig 2B).

\section{LOCATION AND SIZE OF NON-DEPRESSED}

MUCOSAL LESIONS

Figure 3A shows the relation between the location and size of non-depressed mucosal lesions. Among 3605 mucosal lesions, the incidence of lesions $5 \mathrm{~mm}$ or less in diameter was $38 \%$ $(178 / 468)$ in the rectum, 39\% $(476 / 1212)$ in the left colon, and $59 \%(1045 / 1774)$ in the 

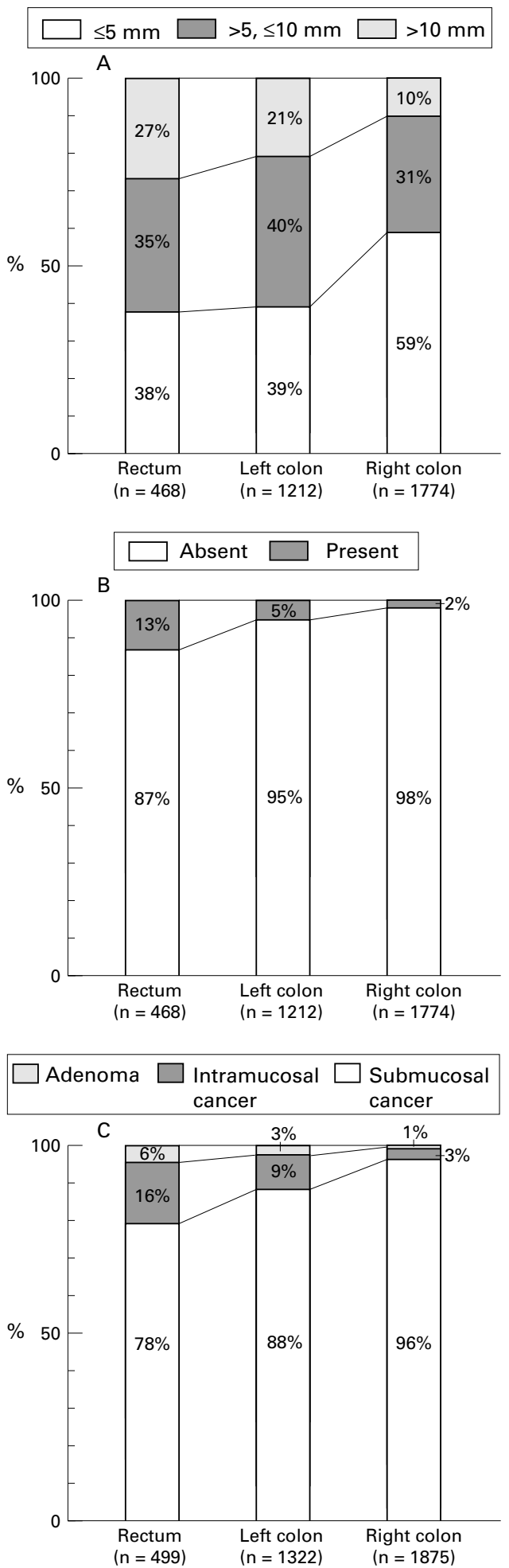

Figure 3 (A) Relation between the location and size of non-depressed mucosal lesions. (B) Relation between the location and incidence of villous components in the non-depressed mucosal lesions. (C) Location of mucosal lesions and submucosal cancers.

right colon, while the incidence of lesions larger than $10 \mathrm{~mm}$ was $27 \%(127 / 468)$ in the rectum, $21 \%(254 / 1212)$ in the left colon, and $10 \%$ $(185 / 1774)$ in the right colon. We observed significant differences in the distribution of the size of mucosal lesions among the three locations (rectum $v$ right colon, left colon $v$ right colon: $\mathrm{p}<0.0001$; rectum $v$ left colon: $\mathrm{p}=$ 0.0186).

LOCATION AND HISTOLOGY OF MUCOSAL LESIONS AND SUBMUCOSAL CANCERS

Figure 3B,C shows the relation between location and histology. Among non-depressed mucosal lesions, the incidence of villous components was $13 \%(62 / 468)$ in the rectum, $5 \%(63 / 1212)$ in the left colon, and $2 \%$ $(32 / 1774)$ in the right colon $(\mathrm{p}<0.0001$ in each group) (fig 3B). None of the depressed type mucosal lesions had villous components. The ratio of submucosal cancers to mucosal lesions was $0.064(30 / 469)$ in the rectum, 0.034 (43/1279) in the left colon, and 0.010 (18/ 1857 ) in the right colon (rectum $v$ right colon, left colon $v$ right colon: $\mathrm{p}<0.0001$; rectum $v$ left colon: $p=0.0105)$ (fig 3C).

MACROSCOPIC TYPE AND ADENOMATOUS COMPONENTS IN SUBMUCOSAL CANCERS

An adenomatous component was observed in 63 of $86(73 \%)$ non-depressed and in none of five $(0 \%)$ depressed type submucosal cancers $(\mathrm{p}=0.0021)$.

\section{Discussion}

Recently, differentiating between flat and depressed type neoplastic lesions has been proposed to be important in recognising the existence of a de novo pathway different from the adenoma-carcinoma sequence. ${ }^{92021}$ Some reports have considered small elevated lesions to be the flat type. ${ }^{22-24}$ However, it is not clear whether these small elevated lesions are included in the polypoid pathway or the de novo pathway. This is one of the reasons why the existence of the de novo pathway is controversial. In this study, we classified mucosal lesions endoscopically into depressed and nondepressed types, and we included small lesions of $5 \mathrm{~mm}$ or less in diameter.

Shimoda and colleagues ${ }^{25}$ proposed that early colorectal cancers could be histologically classified into polypoid and non-polypoid growth, and reported that this categorisation reflected the carcinogenesis pathway. Kato and colleagues $^{18}$ proposed the subclassification of non-polypoid growth into depressed and flat types, and reported that the depressed type retained the characteristics of a de novo pathway morphologically and genetically, whereas the flat type did not. We classified submucosal cancers into depressed and nondepressed types histologically, and found that none of the depressed type had an adenomatous component whereas $73 \%$ of the nondepressed type did. These results suggest that our classification of submucosal cancers may reflect different carcinogenesis pathways.

Bedenne and colleagues ${ }^{26}$ and Ishii and colleagues ${ }^{21}$ reported that de novo cancers were predominant in the right colon. In our study, 83 of $151(55 \%)$ depressed type mucosal lesions and three of five $(60 \%)$ depressed type submucosal cancers were located in the right colon. Thus, some invasive cancers, especially in the right colon, may develop from depressed 
type mucosal lesions, although the incidence of the depressed type is much lower than that of non-depressed lesions.

In the national polyp study, ${ }^{27} 8 \%$ of all mucosal lesions were located in the rectum, $61 \%$ in the left colon, and $31 \%$ in the right colon. In our study, of 3605 mucosal lesions, only $13 \%$ were located in the rectum, $36 \%$ in the left colon, and $51 \%$ in the right colon. In both studies, the proportion of mucosal lesions was relatively low in the rectum. However, it has been reported that about half of all colorectal cancers are localised in the rectosigmoid area. ${ }^{4}$ There is a discrepancy between the incidence and location of mucosal lesions and advanced cancers.

In the national polyp study, ${ }^{27}$ large $(>10$ $\mathrm{mm}$ ) polyps were observed significantly more often in the distal colon than in the proximal colon. In our study, the proportion of lesions larger than $10 \mathrm{~mm}$ was higher in the rectum and the left colon than in the right colon. Histologically, a villous component in mucosal lesions was observed more often in the rectum than in the right and left colon. A villous component is considered to be associated with a high malignant potential. ${ }^{27-32}$ The ratio of submucosal cancers to mucosal lesions was 0.064 $(30 / 469)$ in the rectum, $0.034(43 / 1279)$ in the left colon, and $0.010(18 / 1857)$ in the right colon. In patients with familial adenomatous polyposis, the initial advanced cancer is commonly observed in the distal colon. ${ }^{33}$ These results suggest that mechanisms that promote the progression of mucosal lesions may be implicated in carcinogenesis in the left colon and the rectum.

In conclusion, there may be mechanisms that promote the progression of mucosal lesions to invasive cancer in the left colon and rectum, and a de novo pathway from the depressed type may be implicated in some cancers of the right colon.

This work was supported in part by a Grant-in-Aid for Cancer Research from the Ministry of Health and Welfare of the Japanese Government.

1 Bos JL, Fearon ER, Hamilton SR, et al. Prevalence of ras gene mutations in humann colorectal cancers. Nature 1987;327:293-7.

2 Baker SJ, Fearon ER, Nigro JM, et al. Chromosome 17 deletions and $\mathrm{p} 53$ gene mutations in colorectal carcinomas. Science 1989;244:217-21.

3 Vogelstein B, Fearon ER, Hamilton SR, et al. Genetic alterations during colorectal tumor development. $N$ Engl $₹$ Med tions during color

4 Morson BC. Precancerous and early malignant lesions of the large intestine. Br F Surg 1968;55:725-31.
5 Lane N. The precursor tissue of ordinary large bowel cancer. Cancer Res 1976;36:2669-72.

6 Lescher TC, Dockerty MB, Jackman RJ, et al. Histopathology of the large colonic polyp. Dis Colon Rectum 1967;10:118-24.

7 Kuramoto S, Oohara T. Minute cancers arising de novo in the human large intestine. Cancer 1988;61:829-34.

8 Iishi H, Kitamura S, Nakaizumi A, et al. Clinicopathological features and endoscopic diagnosis of superficial early adenocarcinomas of the large intestine. Dig Dis $S_{C i}$ 1993;38:1333-7.

9 Kudo S. Endoscopic mucosal resection of flat and depressed type of early colorectal cancer. Endoscopy 1993;25:455-61.

10 Fujii T, Rembacken BJ, Dixon MF et al. Flat adenomas in the United Kingdom: are treatable cancers being missed? the United Kingdom: are trea

11 Yamagata S, Muto T, Uchida Y, et al. Lower incidence of K-ras codon 12 mutation in flat colorectal adenomas than in polypoid adenomas. Fpn f Cancer Res 1994;85:147-51.

12 Fujimori T, Satonaka K, Yamamura-Idei Y, et al. Noninvolvement of ras mutations in flat colorectal adenomas and carcinomas. Int $\mathcal{F}$ Cancer 1994;57:51-5.

13 Minamoto T, Sawaguchi K, Mai M, et al. Infrequent K-ras activation in superficial-type (flat) colorectal adenomas and carcinomas. Cancer Res 1994;54:2841-4.

14 Kaneko K, Fujii T, Kato S et al. Growth pattern and genetic changes of colorectal carcinoma. fpn f Clin Oncol 1998;28: 196-201.

15 Langman J. Digestive system. Medical embryology. 5th ed. Baltimore: Williams \& Wilkins, 1985:235-43.

16 Bufill JA. Colorectal cancer: evidence for distinct genetic categories based on proximal or distal tumor location. Ann Intern Med 1990;113:779-88.

17 Delattre O, Olschwang S, Law DJ, et al. Multiple genetic alterations in distal and proximal colorectal cancer. Lancet 1989;12:353-6.

18 Kato S, Fujii T, Oda Y, et al. Difference of genetic alterations between polypoid, flat and depressed growth-type colorectal cancers [abstract]. Gastroenterology 1997;112:A589.

19 Japanese Research Society for Cancer of the Colon and Rectum. General rules for clinical and pathological studies on cancer of the colon, rectum and anus. Fpn f Surg 1983; 13:557-98.

20 Kuramoto K, Oohara T. Flat early cancers of the large intestine. Cancer 1989;64:950-5.

21 Iishi $\mathrm{H}$, Tatuta $M$, Tsutsui $\mathrm{S}$, et al. Early depressed adenocarcinomas of the large intestine. Cancer 1992;69: adenocarcing 2406 .

22 Wolber RA, Owen DA. Flat adenomas of the colon. Hum Pathol 1991;22:70-4.

23 Muto T, Kamiya J, Sawada T, et al. Small "flat adenoma" of the large bowel with special reference to its clinicopathologic features. Dis Colon Rectum 1985;28:847-51.

24 Adachi M, Muto T, Okinaga K, et al. Clinicopathologic features of the flat adenoma. Dis Colon Rectum 1991;34:981-6.

25 Shimoda T, Ikegami M, Fujisaki J, et al. Early colorectal carcinoma with special reference to its development de novo. Cancer 1989;64:1138-46.

26 Bedenne L, Faivre J, Boutron MC, et al. Adenomacarcinoma sequence or "De novo" carcinogenesis? Cancer 1992;69:883-8

27 O'Brien MJ, Winawer SJ, Zauber AG, et al. The national polyp study: patient and polyp characteristics associated with high grade dysplasia in colorectal adenomas. Gastroenterology 1990;98:371-9.

28 Hermanek P, Frühmorgen P, Guggonmoos-Holzmann I, et al. The malignant potential of colorectal polyps: a new statistical approach. Endoscopy 1983;15:16-20.

29 Gillespie PE, Chambers TJ, Chan KW, et al. Colonic adenomas: a colonoscopy survey. Gut 1979;20:240-5.

30 Muto T, Bussey HJR, Morson BC. The evolution of cancer of the colon and rectum. Cancer 1975;36:2251-70.

31 DiSario JA, Foutch PG, Mai HD, et al. Prevalence and malignant potential of colorectal polyps in asymptomatic, average-risk men. Am f Gastroenterol 1991;86:941-4.

32 Atkin WS, Morson BC, Cuzick J. Long-term risk of colorectal cancer after excision of rectosigmoid adenomas. N Engl tal cancer after excision of
$\mathcal{7}$ Med 1992;326:658-62.

33 Bussey HJR. Familial polyposis coli: family studies, histopathology, differential diagnosis, and results of treatment. Baltimore: The Johns Hopkins University Press, 1975:9-17. 